\title{
Synthesis of Emulsion-templated Porous Polycaprolactone
}

\author{
Chenchen XIAO ${ }^{\mathrm{a}}$, Shengmiao $\mathrm{ZHANG}^{* \mathrm{~b}}$ and Jianding $\mathrm{CHEN}^{\mathrm{c}}$ \\ ${ }^{1}$ School of Materials Science and Engineering, East China University of Science and Technology, \\ Shanghai 200237, China; \\ a xiaochenchen900906@163.com, ${ }^{\mathrm{b}}$ shmzhang@ecust.edu.cn, ${ }^{\mathrm{c}}$ jiandingchen@ecust.edu.cn
}

\begin{abstract}
Emulsion-templated porous materials have gained extensively in applications due to their low density and high porosity. However, by far most this type porous polymers are synthesized using conventional radical polymerization and most of the reactions are thermally initiated. Expanding the polymerization mechanisms available for emulsion-templated polymers synthesis is still highly desired. In this work, Diel-Alder (DA) reaction was used to synthesize emulsion-templated macroporous polycaprolactone (PCL). These macroporous polymers were prepared by DA reaction of polycaprolactone pendant with multiple furan group (PCL-furan) and 1,6-bis(maleimide)hexane (BisM) via a high internal ${ }^{1}$ phase emulsion as template. The porous materials have a typical structure of emulsion-templated ${ }^{2}$ materials.
\end{abstract}

\section{Introduction}

Emulsion-templated porous materials have gained extensively in applications such as scaffold for tissue engineering, water purification, solid phase supports for catalysis, and membranes for separation processes due to their low density and high porosity[1]. In this method, high (or medium) internal phase emulsion HIPE (or MIPE) is often used as template where the volume fraction of the dispersed phase exceeds $74 \%[2]$. By far most of this type porous polymers are synthesized using conventional radical polymerization and most of the reactions are thermally initiated[1]. However, some important polymers, such

* Corresponding author: xiaochenchen900906@163.com 
as polycaprolactone and poly(lactic acid), can't be synthesized by radical polymerization. Recently, much of the HIPE-templated polymers research and development has focused on expanding the polymerization mechanisms available for emulsion-templated polymers synthesis. Great efforts have focused upon a variety of polymerization-related issues including thiol-ene and thiol-yne reactions[3], ring-opening metathesis polymerization (ROMP)[4].

During the course of expanding the polymerization mechanisms available for synthesis of emulsion-templated polymers, we considered that the use of Diels-Alder (DA) reaction would be an attractive alternative. DA reaction is one of the most common reactions used in organic chemistry, which involves a straightforward [4 +2] cycloaddition reaction between an electron-rich diene (i. e. furan and its derivatives) and an electron poor dienophile (i. e. maleic acid and its derivatives) to form a stable cyclohexene adduct[5]. This reaction requires a very low energy to form a cyclohexene ring, can conducted at moderate temperature in gentle condition, and it allows the formation and functionalization of numerous molecules.

Herein, macroporous polycaprolactone was synthesized with DA reaction in a Span 80 stabilized water-in-oil (w/o) HIPE. Polycaprolactone pendant with multiple furan group (PCL-furan) and 1,6-bis(maleimide)hexane (BisM) were synthesized as reactants. And the resulting porous materials have a typical structure of emulsion-templated materials.

\section{Experimental Section}

\subsection{Materials}

The E-Caprolactone (CL), furfuryl glycidyl ether (FGE), furfuryl alcohol (FAL), 1,5,7-Triazabicyclo [4.4.0] dec-5-ene (TBD) and Span 80 were purchased from Sigma-Aldrich and used as received. Toluene, N,N-dimethylformamide (DMF, 99.8\%) (Shanghai Lingfeng Chemical Reagent Co, Ltd, China) were distilled under a reduced-pressure nitrogen atmosphere. 1,6-Diaminohexane, maleic anhydride, acetic anhydride, sodium acetate and triethylamine (Shanghai Lingfeng Chemical Reagent Co, Ltd, China) were used as received. All aqueous solutions were prepared using ultrapure water with a resistance of $18.25 \mathrm{M} \Omega$.

\subsection{Synthesis of PCL-furan multidiene (PCL-Furan)}

The PCL-Furan was obtained following a previously described procedure[6]. Synthesis of PCL-furan hydrophobic multidiene was shown in Scheme 1. CL 15.62 g, FGE 4.2 g, 
FAL $0.134 \mathrm{~g}$, TBD $0.18 \mathrm{~g}$ and hydroquinone $0.156 \mathrm{~g}$ were added to a $100 \mathrm{ml}$ three-neck flask equipped with a condenser, stirring at $110^{\circ} \mathrm{C}$ under $\mathrm{N}_{2}$ for $6 \mathrm{~h}$. Then the mixture was cooled down to room temperature, and dissolved in $\mathrm{CHCl}_{3}$. The solution was precipitated with ethanol at $0{ }^{\circ} \mathrm{C}$. The precipitate was dried under vacuum at room temperature for $24 \mathrm{~h}$. Yield: 70\%. IR ( $\mathrm{KBr}$, thin film, $\left.\mathrm{cm}^{-1}\right)$ : $732.0\left(\mathrm{CH}_{2}\right), 1189.7$ (C-O-C), $1726.3(-\mathrm{O}-\mathrm{C}=\mathrm{O})$. ${ }^{1} \mathrm{H}-\mathrm{NMR}\left(400 \mathrm{MHz}, \mathrm{CDCl}_{3}, \mathrm{ppm}\right):$ 7.4, 6.3 (m, 3H, furan), 5.1 (s, 2H, $-\mathrm{CH}_{2}$ ), 3.6 (t, $2 \mathrm{H}$, $\mathrm{O}-\mathrm{CH}_{2}-\mathrm{C}$ ), $\mathrm{x}: \mathrm{y}=11.8: 1$. Gel permeation chromatography (GPC) analysis of the polymer showed $\mathrm{Mw}=12890$ and $\mathrm{Dp}=1.58$.

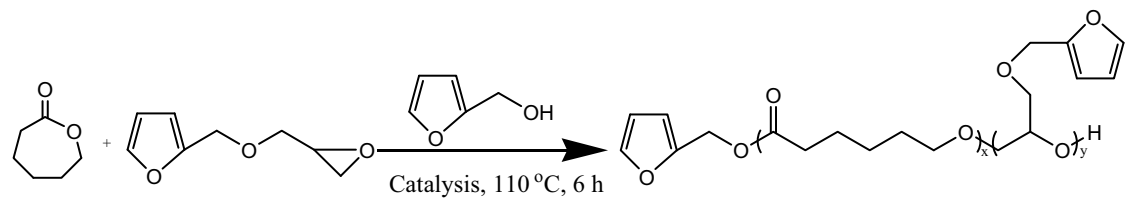

Scheme 1. Synthetic route for formation of PCL-Furan

\subsection{Synthesis of 1,6-bis(maleimide)Hexane (BisM)}

The BisM was obtained according to the method mentioned in the literature[7]. 1,6-Diaminohexane $11.62 \mathrm{~g}$ was added in a $250 \mathrm{ml}$, three-necked, round-bottomed flask under stirring to a solution of $60 \mathrm{ml}$ freshly distilled DMF including maleic anhydride $19.6 \mathrm{~g}$ in it. The temperature rose to $105^{\circ} \mathrm{C}$, then the opaque changed to yellow. Continue stirring for $30 \mathrm{~min}$ at $90{ }^{\circ} \mathrm{C}$. Acetic anhydride $40.8 \mathrm{~g}$, sodium acetate $0.25 \mathrm{~g}$ and triethylamine $4 \mathrm{~g}$ were then added to the reaction mixture, during the following $5 \mathrm{~min}$, the solution turned to dark brown. After cooling, the resulting brown precipitate was filtered several times and washed with water before drying. Pale yellow crystals were obtained. As shown in Scheme 2. Yield: 73\%. IR (KBr, thin film, $\left.\mathrm{cm}^{-1}\right): 2940.2\left(\mathrm{CH}_{2}\right), 1693.7(\mathrm{C}=\mathrm{O}), 1240.9(\mathrm{C}-\mathrm{N}), 1374.7$ (=CH). ${ }^{1} \mathrm{H}-\mathrm{NMR}\left(400 \mathrm{MHz}, \mathrm{CDCl}_{3}, \mathrm{ppm}\right): 6.68$ (s, 4H, $\left.\mathrm{CH}=\mathrm{CH}-\right), 3.46$ (t, 4H, N-CH $)$, $1.61\left(\mathrm{~m}, 4 \mathrm{H},-\mathrm{CH}_{2}\right), 1.29\left(\mathrm{~m}, 4 \mathrm{H},-\mathrm{CH}_{2}\right)$.

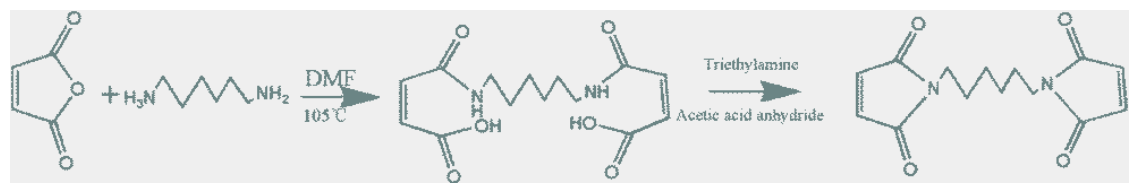

Scheme 2. Synthetic route for formation of BisM 


\subsection{Preparation and characterization of porous materials}

The oil phase composed of toluene $(20 \mathrm{ml})$, Span80 (2.0 g), PCL-Furan $(2.57 \mathrm{~g}, 0.2$ mmol, containing furan of $1.9 \mathrm{mmol})$ and BisM (0.26 g, containing maleimide of $1.9 \mathrm{mmol})$ was added to a $50 \mathrm{ml}$ beaker. The oil phase was stirred at $600 \mathrm{rpm}, 4 \mathrm{ml}$ the water phase containing $\mathrm{NaCl}$ of $0.2 \mathrm{~mol} / \mathrm{L}$ was dropwise added to the oil phase. After the addition of water phase was completed, the mixture was further stirred for $5 \mathrm{~min}$, then put it in an oven for $24 \mathrm{~h}$ at room temperature and subsequently freezing-dried.

The phase behavior of the HIPE was evaluated by measuring the delta backscattering of monochromatic light $(\lambda=880 \mathrm{~nm})$ from the emulsion employing an optical analyzer, Turbiscan Lab Expert (Formulaction, France). As soon as the preparation of the HIPE was completed, it was moved to a flat bottomed cylindrical glass tube $(70 \mathrm{~mm}$ height, $27.5 \mathrm{~mm}$ external diameter). The glass tube was placed in the instrument, and the backscattering of light from emulsion was then periodically measured along the height at $25{ }^{\circ} \mathrm{C}$. The results were presented as the sedimentation profile, i.e., backscattering versus time. SEM image of Au-coated porous material was taken by a Hitachi S-3400N SEM. The average void diameter of the polyHIPEs was estimated from the SEM images. And at least 100 voids were measured for each sample.

\section{Results and Discussion}

As shown in Fig. 1, Turbiscan analysis of this HIPE showed that the backscattering intensity of the emulsion deceased slightly at the beginning of the test, then kept constant during $24 \mathrm{~h}$ since it was prepared, which suggested that this system could be emulsion-templating for porous materials.

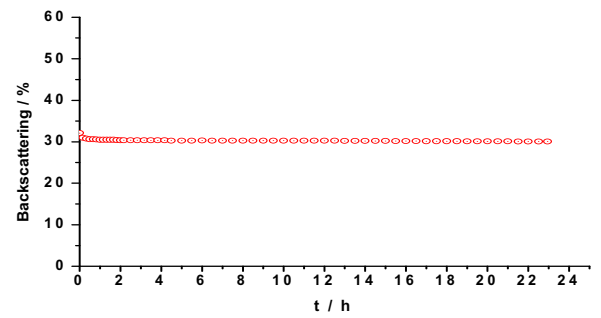

Fig. 1. Backscattering data of the HIPE at $25^{\circ} \mathrm{C}$, and these data were represented as a function of time. 
As shown in Fig. 2, DA reaction of PCL-furan and BisM resulted a porous polymers with a well-defined open-cell porous structure, and the average void diameter from the SEM images was $22 \pm 4 \mu \mathrm{m}$, just like the typical structure of the porous polymers from the radical polymerization of HIPE[2]. This result meant that the DA reaction could be practical reaction approach for preparation of HIPE-templated porous materials.

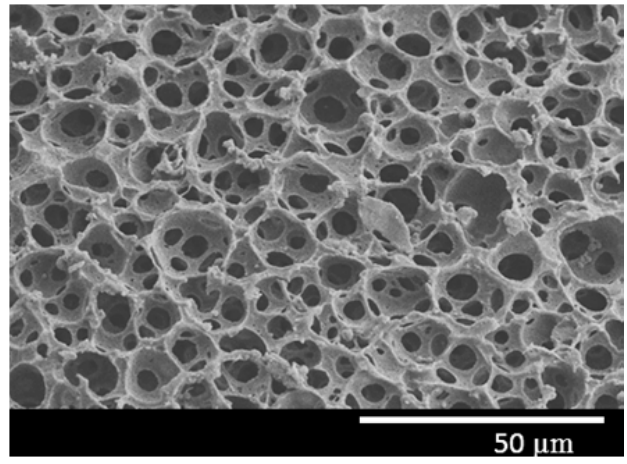

Fig. 2. SEM images of PCL-based porous materials.

\section{Summary}

Emulsion-templated macroporous PCL was prepared via DA reaction between PCL-furan and 1,6-bis(maleimide)hexane in a high internal phase emulsion template. The porous materials have a typical structure of emulsion-templated materials, and the average void diameter of the obtained polyHIPEs sample was $22 \pm 4 \mu \mathrm{m}$.

\section{References}

1. S. Silverstein, PolyHIPEs: Recent advances in emulsion-templated porous polymers, Prog. Polym. Sci., 2014, 39, 199-234.

2. N. R. Cameron, High internal phase emulsion templating as a route to well-defined porous polymers, Polymer, 2005, 46, 1439-1449.

3. L. Kircher, P. Theato, N. R. Cameron, Reactive thiol-ene emulsion-templated porous polymers incorporating pentafluorophenyl acrylate, Polymer, 2013, 54, 1755-1761.

4. H. Deleuze, R. Faivrea, V. Herroguez, Preparation and functionalisation of emulsion-derived microcellular polymeric foams (polyHIPEs) by ring-opening metathesis polymerisation (ROMP), Chem. Commun., 2002, 2822-2823.

5. H. C. Kolb, M. G. Finn, K. B. Sharpless, Click chemistry: diverse chemical function from a few good reactions, Angew. Chem. Int. Ed., 2001, 40, 2004-2021.

6. H. Mallek, C. Jegat, N. Mignard, M. Abid, S. Abid, M. Taha, Reversibly crosslinked self-healing PCL-based networks, J. Appl. Polym. Sci, 2013, 129, 954-964.

7. G. Kossmehl, H. I. Nagel, A. Pahl, Cross-linking reactions on polyamides by bis- and tris(maleimide)s, Die Angewandte Makromolekulare Chemie, 1995, 227, 139-157. 